the coarser stratified rocks-grits, sandstones, \&c.-lends some support to this view, by showing that, as we go back in time, a larger proportion of their materials, cateris paribus, has been derived from crystalline rocks, and that even the fragments, obviously of sedimentary origin, exhibit signs of some mineral change; that is to say, the mudstones and sandstones in the later grits are apt to be represented in the earlier by phyllites and quartzites.

So the results of microscopic study, in alliance with, not divorced from, work in the field, iead us to the conclusion that in the early ages of this globe's history conditions generally prevailed which became gradually, perhaps even rapidly, rare and local ; or, in other words, that in geology the uniformitarian doctrine must not be stated in terms wholly unlimited, though, since this was first enunciated by Lyell, nothing has been discovered to shake our faith in its general truth, or to resuscitate the catastrophic hypothesis which it replaced. But geologists are forbidden by students of physics to regard the universe as a "self-winding clock." The latter affirm, and the former frankly admit, that this globe through long ages has been losing heat by radiation; that there was a time when the temperature of its surface far exceeded that of molten iron: a temperature which now would be reached only at a depth of many miles. If this be so, the conditions under which rocks were formed on the surface of the globe in early days must have been very different from those which subsequently prevailed. Suppose, for example, this surface to have been just white-hot-namely, at a temperature much below that at which most, if not all lavas, consolidate. In that case the ocean would be vapour, and the weight of the atmosphere would be augmented by that of a shell of water of the area of the globe, and two miles in thickness; or, in other words, the atmo:pheric pressure would be about 350 times its present amount. If so, even a lava-flow would consolidate under a pressure equivalent to that of some $400 J$ feet of average rock. But after the surface temperature had become low enough to permit the seas to be gathered together, and the atmospheric pressure had become normal; after rain and rivers, winds and waves, had commenced their work ; after sediments, other than the "dust and a-hes" of volcanoes, had begun to accumulate; still these at a short distance below the surface would find a very different environment from that which now exists. It has been proved by Lord Kelvin that at the end of about one twenty-fifth portion of the whole time which has elapsed since the first solidification of the earth's crust, the underground temperature must have risen at nearly six times its present rate. To reach a zone, the general temperature of which is $212^{\circ} \mathrm{F}$., it would now be necessary to descend, as a general rule, at least 8200 feet, and probably rather more. But in those early days the crust would have been at this temperature at a depth of about 1600 feet, and at 10,000 feet it would have risen to $1050^{\circ} \mathrm{F}$., instead of $250^{\circ} \mathrm{F}$., which now would be exceptionally high. To this depth many rocks, both in Palæozoic and later ages, have been buried, and they have emerged practically unchanged. Hence it follows that the latter temperature is comparatively ineffective; the former, however, could not fail to facilitate mineral changes and the development of coarsely crystalline structures.

These changes, these structures, have been produced in sedimentary rocks in the immediate neighbourhood of a large mass of intrusive igneous rock, such as a coarse granite. To what temperature the former have been raised cannot be ascertained. Suppose, however, it were $1500^{\circ} \mathrm{F}$., which probably is not a very erroneous estimate, this temperature, at the epoch mentioned, would be found at a depth of 15,000 feet. It is now, probably, at least 15 miles beneath the surface. In other words, the zone at which marked mineral changes could be readily produced, quickly sank, and has long since reached a depth practically unattainable. The subterranean laboratory still exists, but the way to it was virtually closed at a comparatively early period in the earth's history.

Another effect of this rapid downward increase of temperature must not be forgotten. When it amounted to $I^{\circ} \mathrm{F}$. for every Io feet of descent, a temperature of $2000^{\circ} \mathrm{F}$. would have been reached at a depth of not quite four miles. This would be rather above the melting-point of many rocks, if they were at the surface; so that, even under the pressure, they would be either very near it or imperfectly solid. If the thickness of the crust were only about four miles, flexures would be readily produced, and the effects of tidal stres es would be considerable ; but even if the earth had become solid as a whole, there would have been large masses of rock, comparatively near to the surface, in an unstable condition, and thus liable locally to slow deformations, displacements, fluxional movements, and intrusion into other masses already at a high temperature, with the result of partial melting down and mutual reactions. Disturbances such as these, slow, but constantly recurring, would produce structures imitative of stratification. It is a remarkable coincidence, to say the least, that these structures are characteristic of Archran rocks, and are extremely rare, if ever present, in those of later date.

But some geologists are so rigidly uniformitarian as to shrink from admitting that any portion of the earth's original crust can possibly be preserved. "Take time enough," they say, "and the changes can be made." But will time alone suffice for every kind of change? How long will it be before gunpowder explodes at blood-heat? But passing over this obvious difficulty, we may ask: Is there time enough? So geologists once thought, as fancy travelled back over endless æons.; But they are checked by the physicist : " earth and sun alike," he affirms, "are masses subject to the laws of radiation; these countless millions of years of which you dream will bring you to a period when not only the earth, but also the whole solar system, was nebulous. All the history of your planet, physical as well as vital, so far as it can be covered by your records, must be compressed into a very moderate number of millions of years, for we have to consider the possibilities not only of a cooling earth, but also of a cooling sun." If this be so, and it seems difficult to dispute the decision; if we are forbidden to look back along "the corridors of time" till they vanish in the perspective of infinite distances, it becomes more and more probable that the whole volume of the earth's history is within our reach, and that its opening chapters will some day be deciphered.

The progress which has been made since the microscope was pressed into the service of geology augurs well for the future, if we work in a spirit of scepticism and a spirit of hope. Of scepticism, lest we trust too much either in ourselves or in even the princes of science; for experience proves that the seductive charms of phantom hypothesis may lead all alike astray from the narrow path of truth into the morasses of error. Of hope, for experience also proves that by patient labour and cautious induction many an illusion has been dispelled and many a discovery been made. Our eyes must soon grow dim, our hands become nerveless, but other workers will be found to take warning from our mistakes and to profit by our toil. The veil which shrouds the face of Nature may be never wholly withdrawn, but its fringe has been already raised; even in our own generation :o much has been accomplished that the hope may be indulgt $d$ of at last learning something of the history of these earliest ages, when the earth had but lately ceased to glow, and when the mystery of life began.

\section{THE LADIES' CONVERSAZIONE OF THE}

\section{ROYAL SOCIETY.}

THE Ladies' Conversazione of the Royal Society took place on the evening of June $\mathrm{I}_{5}$ last, and in every way was a distinct success, the attendance being the greatest on record, and all the available space both for the guests and exhibits being fully occupied. The exhibits, although they included a few that were shown at the last soirée, were for the most part new, and the following is a brief summary of the most noticeable of them :-

Dr. H. Hicks, F.R.S., showed the remains of a mammoth found in Endsleigh Street, in March last, at a depth of only 22 feet. The bones were of enormous proportions, and in their proximity was discovered a tusk which was estimated to have been 12 feet in length.

A series of enlarged transparent sections of the fossil plants of the Coal-measures were exhibited by Prof. W. C. Williamson, F.R.S.

Most interesting were the water-colour drawings of Greek temples, \&c., by Mr. F. C. Penrose, which illustrated his current investigations on the astronomical orientation of ancient Greek emples. The drawings included those of the Propylæa, the Temple of the Wingless Victory, Parthenon, west and east fronts of the Parthenon, north portico of the Erechtheum, east portico of the Theseum, and the Temple of Jupiter Olympius.

Mr. W. M. Flinders Petrie showed some excellent water-

NO. I I $\delta 2$, vOL. 46$]$ 
colour drawings of the pavement which he has recently discovered in the Palace of Chuenaten at Tell el-Amarna ( 1400 B.C.) during his recent excavations. This pavement is quite unique in Eyypt, and is especially valuable owing to the marvellous treatment of the plants depicted.

The water-colour sketches exhibited by Prof. F. W. Oliver (for the Scientific Committee of the Royal Horticultural society) illustrated some typical examples of the damage done to plants by London fog. The injuries shown, he said, were exceedingly prevalent amongst cultivated hot-house plants in the London district during this kind of weather, and extended to a considerable distance from the metropolis, cases occurring as far as Cooper's Hill and Dorking. The sulphurous acid of the fog seemed, in many cases, to have acted directly on the living substance of the foliage and leaves, producing these lesions, while in others there seemed to have been evidence of an accumula. tive action of the deposits of sulphuric acid.

Mr. W. Crookes, F.R.S., who at the last soirée repeated some of Tesla's wonderful experiments, exhibited a novelty in the form of burning nitrogen. He employed an electric current of 65 volts and 15 amperes, alternating 130 times a second, passing it through the primary of a large induction coil. From each of the secondary poles, flames became visible, and met at the centre, being composed mainly of burning nitrogen; when the terminals were separated, so that the flames could not strike across but were in consequence extinguished, it was found that by putting them nearer together a lighted taper was sufficient to re-ignite them. The temperature of the flame exceeds slightly that of a good blowpipe, and a spectroscopic examination of the flame itself shows simply a faint and continuous spectrum. $\mathrm{Mr}$. Crookes pointed out that such a method of exciting an induction coil was first employed by Mr. Spottiswoode in 1880, but " it is not known, however, that any chemical explanation of the flame has before now been published."

Mr. A. A. C. Swinton showed some very interesting photographs of electrical discharges that had been obtained by simply causing the discharges to take place across the surfaces of prepared sensitive dry plates, and consequently without the intervention of any lens. The distinctive character of the figures by the two kinds of discharges were very noticeable, so also was the evidence of their oscillatory nature.

Other electrical exhibits u ere :-

An ingenious device for disconnecting the supplier of electricity if a dangerous voltage happened to he established in a house, and a leakage indicator for high tension currents, both exhibited by Messrs. Drake and Gorham.

Electrical discharges over prepared surfaces, by $\mathrm{Mr}$. J. Wimshurst, showing that over imperfectly conducting surfaces of large area branch-like forms of flashes are produced, and with a great difference of potential sparks of seven feet in length can be attained.

High-tension electrical apparatus, by Mr. L. Pyke, for working a considerable number of vacuum tubes from one generating source, the tubes in this case being each connected with terminally connected inductors, themselves counterpoised against two external conductors connected to the terminals of the transformer.

The Director of the Royal Gardens, Kew, exhibited a specimen of a double cocoa-nut (Lodoicea seychellarum), with illustrations showing its germination. This palm is tall and fanleaved, and peculiar to two of the Seychelles Islands ; its fruit weighing from 25 to 30 pounds. At the germination of the seed, "the embryo is gradually pushed out of the seed by the growth of the seed-leaf (cotyledon). One end of this remains attached to the seed, and conveys to the embryo the nutriment derived from the gradual absorption of the endosperm." Three of the drawings and a model had an additional interest in that they were made by the late Major-General Gordon.

Mr. Romanes's exhibits of living rats and rabtits attracted much attention, and would perhaps have attracted slightly more if any of the former animals had by chance got astray. They were illustrative of some of the results of experimental breeding with reference to theories of heredity. The examples clearly showed that the male and female elements did not always so blend together that the offspring presented characters more or less intermediate between those of the parents, but that the progeny sometimes took wholly after the father or wholly after the mother.

Another animal exhibit consisted in a living specimen of a remarkable non-venomous South African snake (Dasypeltis scabra), from the Zoological Society of London. This animal lives solely on birds' egys. Each egg is swallowed whole, and by a muscular contraction of the gullet, its contents flow into the stomach, while the shell is rejected by the mouth in the form of a peliet.

Among the other exhibits we may mention the systematic and simple construction of the dark absorption bands $\mathrm{A}, \mathrm{B}$, and $a$ in the solar spectrum, after Mr. Higgs's photographs, by Prof. A. S. Herschel, F.R.S.; the photographs of stellar spectra, including Nova Aurigæ, Arcturus, \&c., by Mr. Norman Lockyer, F.R.S. ; the photouraphs of leguminous plants for the determination of the fixation of free nitrogen, by Sir J. B. Lawes, Bart, F.R.S., and Dr. J. H. Gilbert, F.R.S.; and an ingenious instrument for measuring the thermal expansion of very minute solid bodies up to high temperatures, and tracing the volume charge of the silicates up to and over the interval of plasticity, by Mr. J. Joly, F.R.S.

The exhibit in theArcuives Room, by the Postmaster-General, was during the whole evening thoronghly appreciated, the Telephone Company's installation being the means by which the guests were able to listen to the music of Salammbo from the grand opera at Paris. Previous to the switching on of the opera, conversation was carried on with some of the officials at the Paris end, and the accuracy with which the peculiarities of the various voices were transmitted was little short of marvellous.

The lantern demonstrations. also attracted considerable attention. Mr. Saville Kent and Mr. C. V. Boys, F.R.S., as at the previous soiré, both showed their photograpbic slides, those of the former dealing with coral reels, \&c., and those of the latter with flyıng bullets. Mr. Norman Lockyer exhibited some photographs taken both at home and foreign Ouservatories, illustrative of the application of photography in astro-physical researches. The slides included some heautiful photographs of stellar spectra and solar prominences, from the Paris Ubservatory; of the moon and Jupiter, taken with the large Lick instrument; of the nebulosity surrounding $\eta$ Argûs, photographed by Dr. Gill, F.R.S. ; of the great February sun-spot, taken in India and forwarded to the Solar Physics Committee ; and of the spectra of Nova Aurigæ and Arcturus, taken at Kensington. The most striking slide of all was that of the great nebula of Orion, taken by Dr. Common, F.R.S., with his five-foot reflector at Ealing. The apparent brilliancy of the stars, and the wonderful tracery in the nebulous parts, appealed to the eye not so much as an image of a slide on a screen, but as a direct view of this beautiful object through the great telescope itself. The slides shown by Mr. E. B. Poulton, F.R.S., were illustrative of the methods by which the originally opaque wings of certain butterflies and moths had become transparent and usually scaleless; numerous stages in the generation of scales were also shown.

\section{THE FOURTH CENTENARY OF COLUMBUS.}

DURING the present year great celebrations will take place in Spain, ltaly, and America, in memory of Columbus and his first adventurous voyage of 1492 . Although no public commemoration is arranged for in this country, the Royal Geographical Society, fully conscious of the momentous nature of that first voyage, and of the enormous expansion of geographical science which has resulted from it, set apart last Monday evening for a special Columbus meeting. The usual exhibition of maps and pictures included a number of early charts of great beauty, and a fine photograph of a contemporary portrait of Columbus, recently made known by Mr. Markham. The paper of the evening, read by Mr. Clements Markham, C.B., F.R.S., was occupied with an account of recent discoveries with regard to Columbus, and the correction of many erroneous ideas widely entertained until ncw. As a critical summary of perhaps one of the most difficult branches of research - that into the actual life of a popular hero enhaloed with centuries of tradition-this paper is of great value. An abstract of it, and of the appendices on other fifteenth century explorers, is given below.

Much new light has been thrown upon the birth and early life of Columbus of late years by the careful examination of monastic and notarial records at Genoa and Savona.

There is no doubt as to the birthplace of Columbus. His father was a wool-weaver of Genoa, whose house was in the Vico Dritto di Ponticelli, which leads from the gate of San 